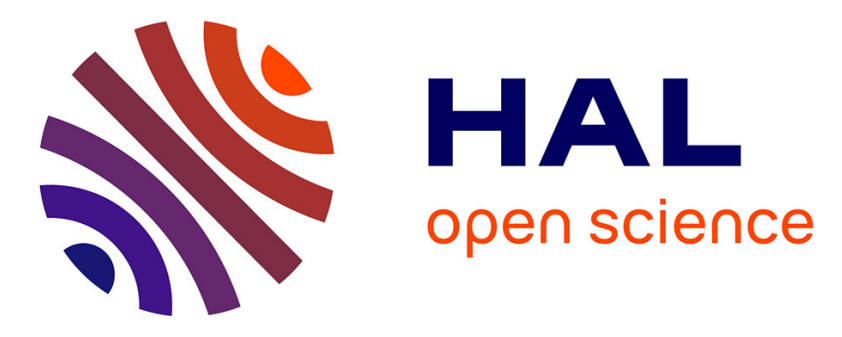

\title{
A 3D Folded Power Inductor with PCB based technology for applications in the $\mathrm{kW}$ range
}

Johan Le Lesle, Corentin Darbas, Florent Morel, Nicolas Degrenne, Rémy Caillaud, Cyril Buttay, Roberto Mrad, Christian Vollaire, Stefan Mollov

\section{- To cite this version:}

Johan Le Lesle, Corentin Darbas, Florent Morel, Nicolas Degrenne, Rémy Caillaud, et al.. A 3D Folded Power Inductor with PCB based technology for applications in the $\mathrm{kW}$ range. APEC, Mar 2019, Anaheim, Californie, United States. 10.1109/APEC.2019.8722295 hal-02076182

\section{HAL Id: hal-02076182 \\ https://hal.science/hal-02076182}

Submitted on 22 Mar 2019

HAL is a multi-disciplinary open access archive for the deposit and dissemination of scientific research documents, whether they are published or not. The documents may come from teaching and research institutions in France or abroad, or from public or private research centers.
L'archive ouverte pluridisciplinaire $\mathbf{H A L}$, est destinée au dépôt et à la diffusion de documents scientifiques de niveau recherche, publiés ou non, émanant des établissements d'enseignement et de recherche français ou étrangers, des laboratoires publics ou privés. 


\title{
A 3D Folded Power Inductor with PCB based technology for applications in the $\mathrm{kW}$ range
}

\author{
Johan LE LESLÉ*†, Corentin DARBAS*, Florent MOREL ${ }^{\dagger}$, Nicolas DEGRENNE*, Rémy CAILLAUD*†, Cyril \\ BUTTAY $^{\dagger}$, Roberto MRAD*, Christian VOLLAIRE ${ }^{\dagger}$ and Stefan MOLLOV* \\ *Mitsubishi Electric R\&D Centre Europe, 1 Allée de beaulieu, 35708 Rennes, France \\ †Université de Lyon, Ecole Centrale de Lyon, INSA de Lyon, UCBL, CNRS, Ampère, F-69361, Ecully, France
}

\begin{abstract}
This paper presents an original 3D folded power inductor concept using Printed-Circuit-Board (PCB) technology. It is low cost for mass production and presents good reproducibility. A partial milling of the PCB is used to allow bending and building the inductor winding. A prototype is designed through an optimisation procedure. The frequency dependency of the series resistance, which widely impacts the losses in power converters, is investigated. Electrical and thermal tests are realised on the inductor to validate the applicability in power converters, e.g buck/boost inductor or EMI filter inductor, in particular differential mode inductor. These tests shows that the proposed inductor is a good candidate for power converters in the $\mathrm{kW}$ range.
\end{abstract}

\section{INTRODUCTION}

The trends in power electronic converters are high power density, low cost and high reliability. Magnetic components are reliable but are generally considered bulky and expensive [1]. Thus, volume and cost reductions are necessary.

Volume is intrinsically linked to magnetic and conductive material properties, as well as thermal management. Some authors proposed to reduce the losses related to air gaps in inductors by using multiple air gaps and proper mechanical process [2]. Others propose advanced thermal management [3]. PCB embedding permits to make use of waste volume space within the PCBs to reduce the apparent volume [4].

Cost is a function of both bill of material (BOM) and process cost for construction and cabling. In the $\mathrm{kW}$ range, the inductive components are typically large and may be connected to screwed cables in some cases, thus requiring manual intervention. PCB integration proposes a new way to manufacture power converters, offer perspectives for cost control through reduction of components, and manufacturing steps [5].

Different inductor types are used in converters. Discrete inductors may be off-the-shelf as in Figure 1.(a). Advantages of this kind of inductors are, simplicity of assembly, as it can be soldered as others SMD components and usually available in large quantity with characterisations from the manufacturer. However, values can be limited for such power range, whereas power converter optimisation leads to precise inductor values which may not be available on the market. To overcome this issue, magnetic cores are wound with copper wires, sometimes Litz wires, to get the required inductor values, see Figure 1.(b). Hence, additional manufacturing steps may be required, not

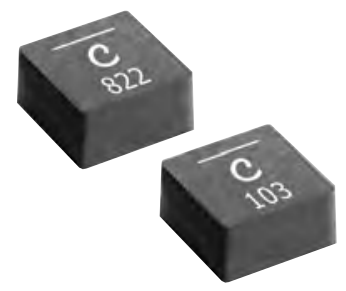

(a)

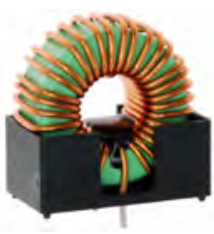

(b)
Figure 1: Examples of discrete inductors. a) Industrial moulded inductor [6]. b) Wound toroidal inductor.

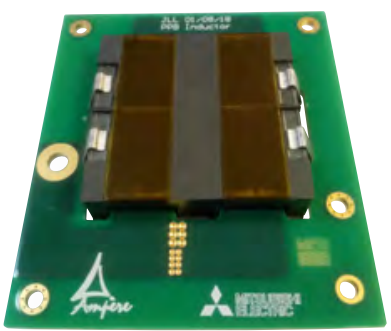

Figure 2: Example of planar inductor

necessarily automated, typically for through hole soldering or screwed inductors. Moreover, in the case of low quantities requirement, custom solutions may be expensive.

Therefore, the use of PCBs, such as with the Planar technology (Figure 2), allows custom designs to be built without the additional step. Planar technology appears to be good tradeoff between performances and cost for $\mathrm{kW}$ level applications. However, the design constraints on the number of windings and the copper cross section are difficult to meet. In addition, the geometry tends to create high inter- winding parasitic capacitances lowering the performances for some applications.

Focusing on PCB based inductors, embedding of magnetic core gains interests. Many winding or core assembly steps are avoided when using PCB manufacturing process. This leads to a more simplified manufacturing process and thus lower manufacturing cost. Design of embedded magnetic is more common for low power applications $(<100 \mathrm{~W})$. For example, an integrated, $13 \times 13 \mathrm{~mm}^{2}, 2 \mathrm{~W}$ dual-outputs gate-driver power supply for $\mathrm{GaN}$ is presented in [7]. The transformer is formed 


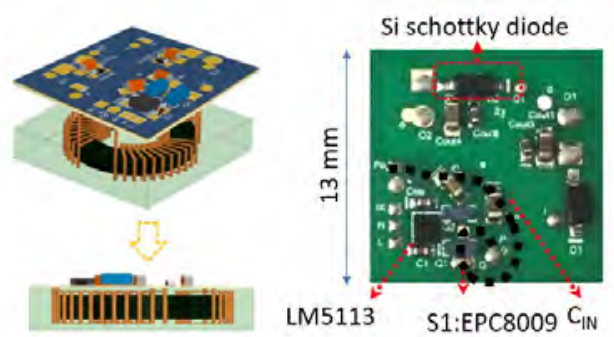

(a)

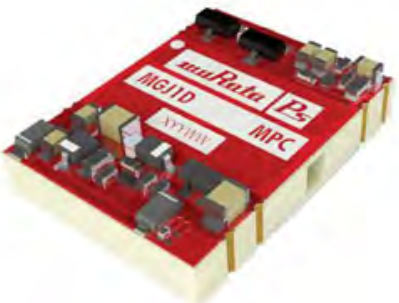

(b)

Figure 3: Isolated power supply for gate-drivers. a) Dual output power supply [7]. b) Isolated power supply from Murata [8]

by embedding a ferrite core in the PCB, the primary and the two secondary windings are formed by tracks and vias. A similar product, $15 \times 20 \mathrm{~mm}^{2}$, isolated power supply for gate drivers, is available from Murata (see Figure 3). A larger $60 \mathrm{~W}$ coupled inductor with square embedded core is also presented in [9]. Thus, this process complies with different core shapes and sizes. Nevertheless, custom core shapes can be considered by coupling the embedding process and magnetic powders [10].

PCB embedding of magnetic core is mainly limited by the thickness of the PCB, thus, integration in the $\mathrm{kW}$ range is still a major challenge. Indeed, the presented examples have a small outside diameter core that it is preferred to handle the lamination process. A New toroidal inductor using embedded core in a $3.3 \mathrm{~kW}$ AC/DC converter is presented in [11]. The embedded toroidal inductor is limited by the thickness of the PCB, requiring specific core geometries and low section per perimeter ratio. This deign results in a flat structure that facilitates the cooling. Furthermore, the top PCB surface can be used for SMD components. However, thin magnetic cores are fragile, thus the lamination process is a very sensitive step.

This paper proposes a new design that uses PCB substrate for forming the windings in a 3D manner. This technology is demonstrated here with a cut toroid magnetic core. The proposed inductor avoids the core thickness limitation brought by PCB embedding, and thus any core sizes can be used. However, it requires a bending step to assemble the windings and the magnetic core. In this paper the targeted application for this new 3D inductor is a Buck Power Pulsating Buffer (PPB) [12]. This type of converter is used in single phase AC/DC or DC/AC converter to avoid bulky DC link Electrolytic capacitors. The inductor value, and the geometry are obtained with the procedure presented in [13]. The objectives for the inductor are high density and low losses.

First, the 3D inductor concept is introduced. Then, all constraints related to such design are presented in the third section. The realised prototypes are presented in the fourth section. Investigation on the performances of the prototype by losses measurements based on calorimetric methods are presented in fifth section.

\section{FOLDED POWER INDUCTOR (FPI) CONCEPT}

The concept uses the PCB process to design the winding of the inductor in the planar style, however, the windings are

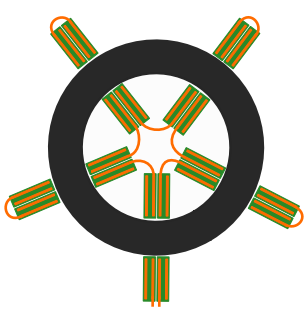

(a)

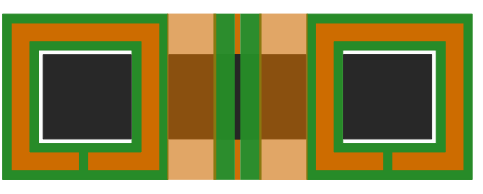

(b)
Figure 4: 3D Inductor concept. a) Axial cross section. b) Radial cross section.

placed around the core. The concept requires at least PCBs with two copper layers for the windings, as it is presented in Figure 4. The winding is composed of several PCB parts connected by "flex" copper. Hence, it is a solder-less design. The inductor is obtained by bending the different PCB parts. The final inductor has a flower shape so two bended PCB parts are named a "petal". The inductor is formed with ferrites cores cut in half (i.e. with two air gaps) and the winding is threaded on the cores. It could also be possible to use powder core [14], the magnetic material can alternatively be molded around the windings [15]. The proposed geometry is mainly limited by the inner diameter of the core and the PCB thickness.

The basic design of each petal with the associated winding for a two layers PCB is presented in Figure 5. One turn and a half is realised on each PCB part using the Top and Bottom layers. Hence, each petal allows three turns to be realised. Thus, this topology limits the number of turns to multiple of three.

Two PCB technologies are foreseen for the realisation of this concept. The first one uses the Wirelaid ${ }^{\mathrm{TM}}$ technology (such as in Jumatech $\mathrm{Gmb}$ ) which embeds thick copper wires which can be used to bend the PCB. The second one corresponds to PCBs with milled area used for bending. This technology is commercially available under the name semi-flex ${ }^{\mathrm{TM}}$ from Wurth Electronik. The price is attractive and delivery times are shorter than Wirelaid ${ }^{\mathrm{TM}}$. This technology is suitable for mass-production. The main limitation of the semi-flex comes from the copper thickness, $60 \mu \mathrm{m}$ for outer layers and $70 \mu \mathrm{m}$ for inner layer. However in this work the selected technology for the prototype is the semi-flex ${ }^{\mathrm{TM}}$ PCB. 


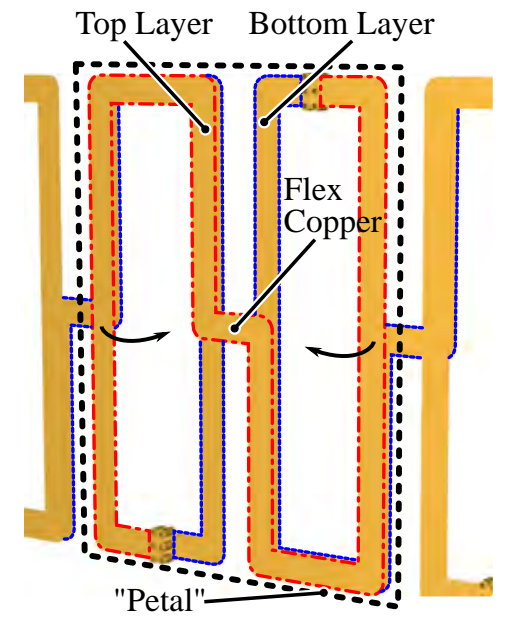

Figure 5: Basic layout of the 3D inductor

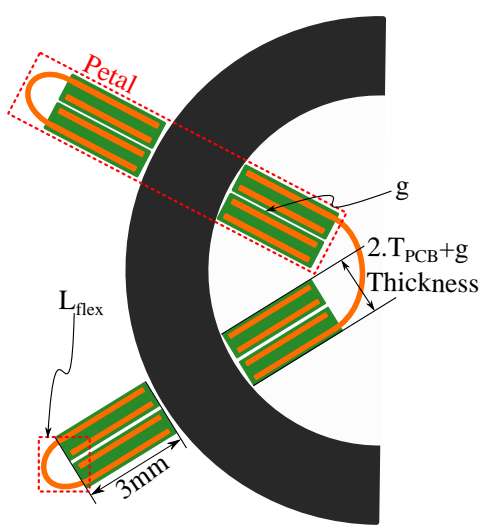

Figure 6: Main dimensions of the petals

\section{INDUCTOR DESIGN}

Before launching any optimisation, mechanical constraints need to be defined according to the PCB process. The track width is set to $3 \mathrm{~mm}$. The inner diameter of the core cannot be less than $6 \mathrm{~mm}$ as the width of the PCB inside the core corresponds to the radius. For a selected core, the maximal number of turns depends on the number of petals. The maximal number of petals is calculated according to the PCB thickness $\left(\mathrm{T}_{\mathrm{PCB}}\right)$, the minimal distance between two petals and the inner perimeter of the core, see Figure 6. For the first design the minimal distance between two petals is set arbitrarily to $3 \mathrm{~mm}$ for thermal concerns to let air flow between two petals.

The length of the flex copper plane is calculated to obtained a $180^{\circ}$ bending angle. It is determined according to the width of one petal that also depends on the PCB thickness $\left(\mathrm{T}_{\mathrm{PCB}}\right)$, and a small gap between the two PCBs (g), as presented in (1).

$$
L_{\text {flex }}=\frac{\pi \cdot\left(2 \cdot T_{P C B}+g\right)}{2}
$$

All the mechanical constraints are defined and used in the optimisation procedure presented in [13]. The inductor must not saturate nor overheat. First, the minimal number of turns
Table I: 3D inductor optimisation results

\begin{tabular}{cc}
\hline Inductance & $20 \mu \mathrm{H}$ \\
\hline $\mathrm{Nb}$ Turns & 15 \\
\hline $\mathrm{Nb}$ Petals & 5 \\
\hline Air Gap & $2 \times 800 \mu \mathrm{m}$ \\
\hline Material & $\mathrm{N} 87$ \\
\hline Core outer Dia. & $23 \mathrm{~mm}$ \\
\hline Core inner Dia. & $14 \mathrm{~mm}$ \\
\hline Core Height & $28 \mathrm{~mm}$ \\
\hline Copper Thickness & $60-70 \mu \mathrm{m}$ \\
\hline Track width & $3 \mathrm{~mm}$ \\
\hline
\end{tabular}

is calculated to obtain the required inductance, then rounded above to the closest multiple of three. The air gap is calculated to avoid the saturation with the redefined number of turns. The copper and the core losses are calculated separately. The copper resistance is calculated according to the copper section, the core geometry and the number of petals. The core losses are calculated with improved generalised Steinmetz equation (iGSE) [11]. The increase in temperature is then calculated. A simple thermal model is employed using the surfaces of the corresponding box enveloping the inductor $\left(\mathrm{S}_{\mathrm{B}}\right)$, the total losses $\left(\mathrm{P}_{\mathrm{L}}\right)$ and constant convection coefficient $(\mathrm{h})$, see (2). Convection coefficient is set to $50 \frac{\mathrm{W}}{\mathrm{m}^{2} \cdot K}$ emulating a cooling system.

$$
\Delta T=\frac{P_{L}}{h \cdot S_{B}}
$$

The maximal temperature is fixed at $100^{\circ} \mathrm{C}$ while the ambient temperature is equal to $60^{\circ} \mathrm{C}$. The optimisation results lead to inductor of fifteen turns (five petals). The selected core material is N87 from EPCOS, three cores B64290L0626X087 are stacked. Dimensions are summarised in the Table I.

\section{PROTOTYPES}

As aforementioned, the low copper section of the semi-flex is limiting when large currents are flowing through the inductor. To overcome this issue, multi-layer PCB is used and some layers are parallelised in the rigid part to achieve a copper cross-section of $0.6 \mathrm{~mm}^{2}$. Concerning the flex parts, large copper planes are used to handle mechanical and electrical stresses.

The semi-flex technology is sufficiently flexible allowing the inductor to be disassembled. The core can be removed from the windings. Two prototypes are proposed. The first one is vertically oriented (see Figure 7.(b)). The second one is horizontally oriented (see Figure 7.(a) and (c)). These prototypes are built with six layers $1.2 \mathrm{~mm}$ Thick PCB. In this case the assumed space $(\mathrm{g})$ is $0.5 \mathrm{~mm}$, thus the length of the flex part is $4 \mathrm{~mm}$. This gives the most homogeneous bending radius.

Regarding size, the horizontal-oriented flex inductor has a box volume of $76.6 \mathrm{~cm}^{3}$ if the connecting pads are included, and $50.65 \mathrm{~cm}^{3}$ if they are not. Therefore, the volume of the proposed inductor is also acceptable for such applications, 


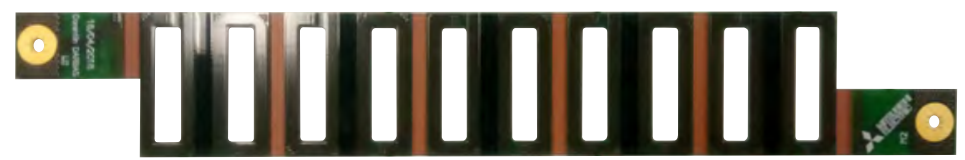

(a)

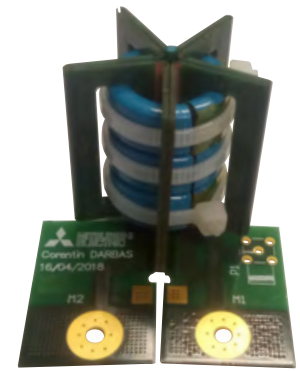

(b)

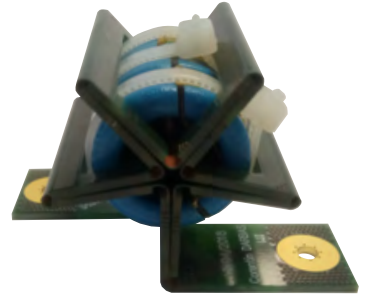

(c)

Figure 7: Semi-flex inductor prototypes. a) Unfolded winding. b) Vertically oriented inductor. c) Horizontally oriented inductor.

$3.3 \mathrm{~kW}$ PPB converter. The surface used by the proposed concept is only $20.35 \mathrm{~cm}^{2}$.

The interactions of fringing flux with the winding are reduced when air gaps are placed between two petals, at equal distance. Therefore, the proximity effects are reduced. In this design, with five petals, the cores are not cut in two identical halves, to ensure the air gaps as far as possible from the petals.

As the evolution of the series resistance is a good performances indicator, the (horizontal) prototype is characterised with a 4294A impedance meter from Agilent. The inductance is higher than the expected value $(20 \mu \mathrm{H})$, see Figure 8.(a). This difference comes from slightly lower air gaps. However, the inductance can be considered constant until $1 \mathrm{MHz}$.

Regarding losses, the proposed inductor presents a good behaviour, see Figure 8.(b), the low frequency series resistance is lower than $50 \mathrm{~m} \Omega$. Skin and proximity effects become significant at $20 \mathrm{kHz}$. The inductor is designed for a converter operating at $140 \mathrm{kHz}$, at this frequency the series resistance is equal to $227 \mathrm{~m} \Omega$. It is 4.5 times the DC resistance, which is acceptable. Nevertheless, the number of parallel layers can be increased to reduce the series resistance to improve the overall performances.

\section{LOSS CALCULATION BASED ON CALORIMETRIC MEASUREMENTS}

The designed inductor should handle a current composed of low $(50 \mathrm{~Hz})$ and high $(140 \mathrm{kHz}$ and harmonics) frequencies. Therefore, a test bench dedicated to losses measurements has been implemented to determine the inductor losses under such conditions. The following presents the experimental set-up with the electrical circuit, the calorimetric enclosure and the associated procedure.

This method of losses measurement is more precise than an electrical measure, especially if the voltage is not sinusoidal. Moreover, the set-up can be simply settled if the DUTs have reasonable size that fits with thermal chamber.

\section{A. Excitation circuit}

The converter topology presented in Figure 9 is used to characterise the inductor. The advantage of this kind of circuit is the possibility to use low voltage and low power DC supply. The test performed hereafter are realised under $30 \mathrm{~V}$. The DC supply is only used to compensate for the losses of the

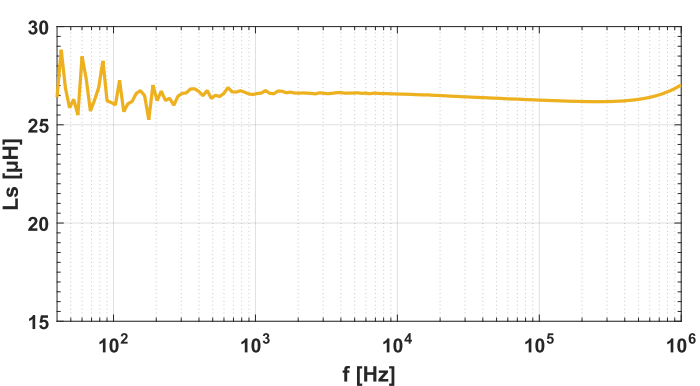

(a)

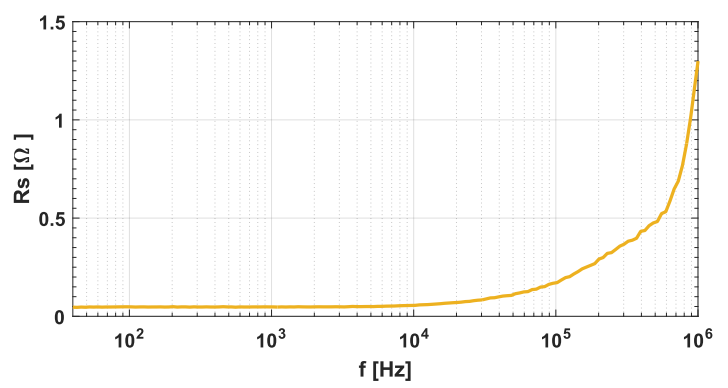

(b)

Figure 8: Impedance characteristics of the proposed PCB inductor. a) Inductance characteristic according to the frequency. b) Series resistance variation according to the frequency.

H-Bridge circuit and the inductor. Nonetheless, the current flowing through the inductor is representative of a typical current in the application. The current is composed of a low frequency component and a high frequency component. The switching frequency is equal to $140 \mathrm{kHz}$. The low frequency current is also controlled by a signal generator.

\section{B. Calorimetric method}

The previous circuit is associated to an inertia calorimetric set-up that is used to measure the losses of the $3 \mathrm{D}$ inductor. All the elements used in the calorimeter are presented in Figure 10. The DUT is immersed in a dielectric solution inside an almost adiabatic enclosure. Novec 7500 (3M) is used as medium. It is a good dielectric liquid (breakdown voltage $>35 \mathrm{kV}$ for $2.54 \mathrm{~mm}$ ). This liquid is usually used for immersion cooling. Moreover, the boiling temperature is $128^{\circ} \mathrm{C}$ which is sufficient for experiment slightly lower than $100^{\circ} \mathrm{C}$. Finally, 


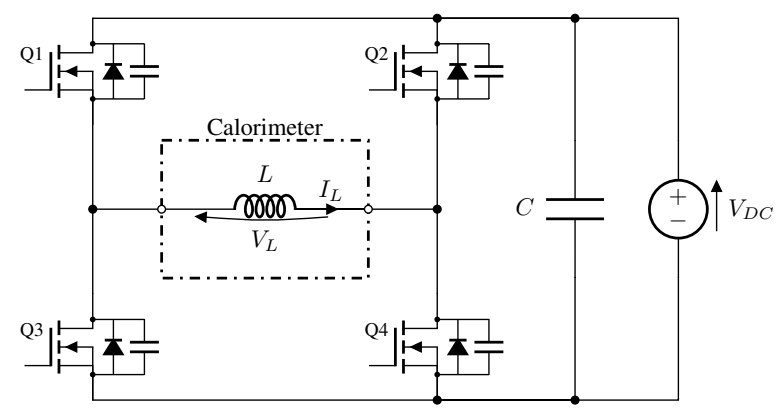

Figure 9: H-Bridge topology used for calorimetric measurements

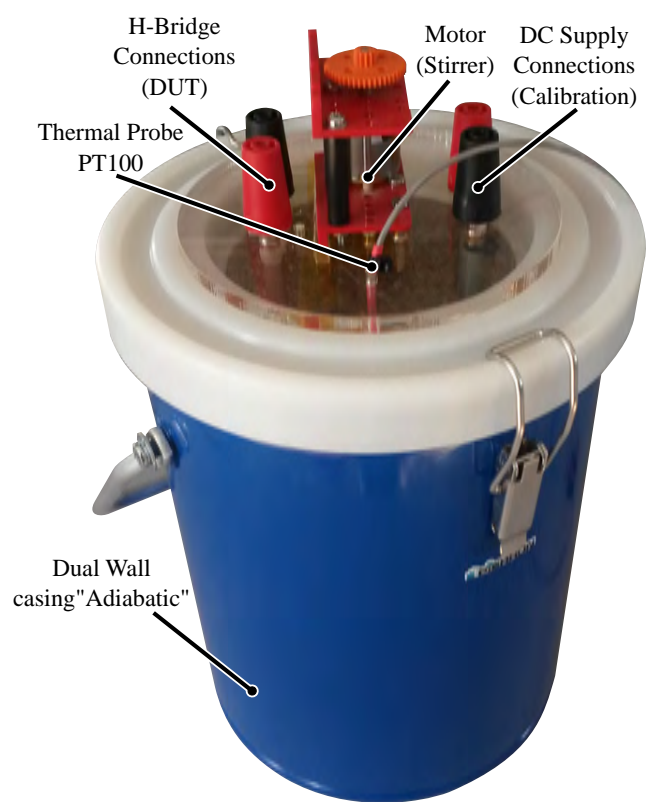

Figure 10: Calorimetric setup with Novec 7500 inside.

it is a non-oily texture, so the DUT is perfectly clean when the experiments are completed.

The temperature of the solution is automatically measured with thermal probe PT1000 connected to a Keithley 2700 precision multimeter. The data acquired with this multimeter is then uploaded on a PC running Matlab using LAN/GPIB gateway (Agilent E5810A). The losses of the device are basically given by (3), where $M_{i}$ are the different masses in the system and $C p_{i}$ the heat capacity of the different elements. With this method a calibration is required before each set of measure.

$$
P_{D U T}=\sum\left(M_{i} \cdot C p_{i}\right) \cdot \frac{d T}{t}
$$

Before any measurement is performed, the temperature inside the calorimeter is raised to $30^{\circ} \mathrm{C}$ (by dissipating some power in the DUT). This ensures that the temperature of the bath is slightly above the ambient temperature and that the heat losses of the calorimeter are controlled. A stirring system ensures an homogeneous temperature in the bath (the stiring motor is kept out of the calorimeter to avoid unwanted

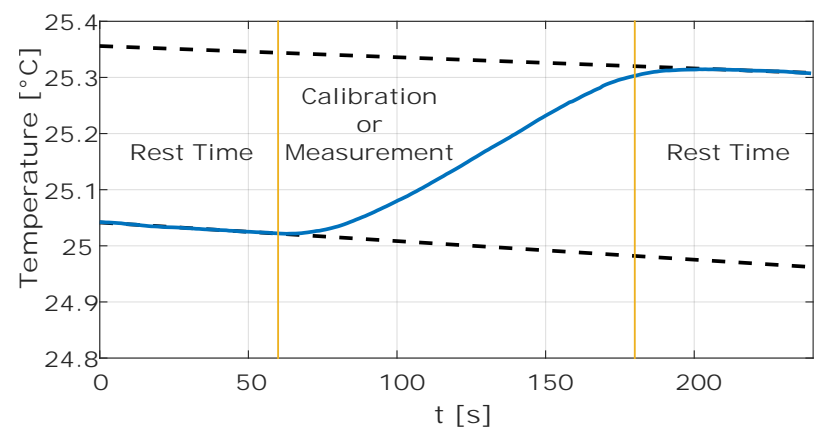

Figure 11: Typical calorimetric curve

heat dissipation). The next step is the calibration of the heat capacity of the calorimeter: a known amount of energy is dissipated in the bath (using an electric resistance, a DC power supply, and voltammetric measurements). The calibration with the resistor allows to identify $\sum\left(M_{i} \cdot C p_{i}\right)$ in (3). Once the calibration has been made, the DUT is operated for a set amount of time, and the corresponding temperature rise is measured (Figure 11). A linear regression is determined from the temperature decreasing slope to calculate the dT. If the enclosure is well thermally insulated, the curves are parallel. The experimental procedure can be summarised as follows.

- Step 1 : Increasing of temperature with the DUT for homogenisation

- Step 2 : Rest time, decreasing of the temperature due to not perfectly adiabatic enclosure

- Step 3 : Impulse of power in the resistance for calibration

- Step 4 : Rest time

- Step 5 : Impulse of power in the DUT

- Step 6 : Rest time

The precision of the set-up is calculated from all sources of errors that includes equipment uncertainty and error from the operator. Two measurements are performed, the first is the calibration and the second is the losses measurements for the DUT. Hence some errors are cumulated. For the calibration, identified errors come from the voltmeter, the amperemeter, the thermal probe and the error on the heating time as the start and stop are not automatic. The global error during the calibration can be calculated by (4). All the errors are presented in Table II. The errors from the voltmeter and amperemeter only depend only on the used range, in this case $10 \mathrm{~V}$ and $10 \mathrm{~A}$, respectively. The absolute error on the temperature measurement cancels out because temperature is measured in a relative way (final temperature minus initial temperature). Only the relative error has an effect, hence the low impact of the temperature measurement on the total measurement error. The highest source of error is on the time: the shorter heating time, the higher the error. The total error on the measurement, for the DUT, is calculated by (5), including the errors on temperature and time plus the error from the calibration. For example, for a heating time of $60 \mathrm{~s}$ during the calibration and the measure, the final error is equal to $4.49 \%$. 
Table II: Measurement errors

\begin{tabular}{cccc}
\hline Equipment & Variable & Error & Percentage \\
\hline \hline Voltmeter U1242B & $\Delta \mathrm{V}$ & $\pm 11 \mathrm{mV} / 10 \mathrm{~V}$ & $0.11 \%$ \\
\hline Ammeter U1242A & $\Delta \mathrm{I}$ & $\pm 65 \mathrm{~mA} / 10 \mathrm{~A}$ & $0.65 \%$ \\
\hline PT1000 Class A & $\Delta \mathrm{dT}$ & $\pm 0.15^{\circ} \mathrm{C}+0.002\left[\mathrm{~T}^{\circ} \mathrm{C}\right]$ & $0.2 \%$ \\
\hline time estimation & $\Delta \mathrm{t}$ & $\pm 1 \mathrm{~s} /$ Heating time & - \\
\hline
\end{tabular}

Hence, calorimetric measures are considered as a good method to determine the losses in the $3 \mathrm{D}$ inductor.

$$
\begin{gathered}
\epsilon_{\text {calib }}=\frac{\Delta V}{V}+\frac{\Delta I}{I}+\frac{\Delta t}{t}+\frac{\Delta d T}{d T} \\
\epsilon_{\text {meas }}=\frac{\Delta t}{t}+\frac{\Delta d T}{d T}+\epsilon_{\text {calib }}
\end{gathered}
$$

\section{Results}

Losses in the inductor are determined for several current values. Three sets of measures are performed, the effective inductor current increases for each measure. The effective current values (including $\mathrm{HF}$ ) are $7.5 \mathrm{~A}_{\mathrm{RMS}}, 10.3 \mathrm{~A}_{\mathrm{RMS}}$ and $12 \mathrm{~A}_{\mathrm{RMS}}$. The inductor nominal current is $10.25 \mathrm{~A}_{\mathrm{RMS}}$. One example of temperature curve that is used to calculate the losses and the corresponding injected current is presented in Figure 12. It corresponds to the test with $10.3 \mathrm{~A}_{\mathrm{RMS}}$ injected in the inductor. The heating time is equal to $60 \mathrm{~s}$ for the two phases of experiment, the calibration and the measures on the DUT. The calculated losses for the three sets of measures are equal to $3.57 \mathrm{~W}, 5.52 \mathrm{~W}$ and $7.18 \mathrm{~W}$, respectively. All these results are presented in Figure 13 including the incertitude of the measurement.

The repartition of losses (between copper and core losses) can be determined according the calorimetric measurements and also impedance measurements. The two components, LF and $\mathrm{HF}$, of the injected current can be used to evaluate the copper losses. In the case of the $5.52 \mathrm{~W}$ total losses, the effective value of the low frequency component is equal to $10 \mathrm{~A}_{\mathrm{RMS}}$ and the effective value of the high frequency component is equal to $1.13 \mathrm{~A}_{\mathrm{RMS}}$. The corresponding series resistances are determined from the impedance measurement (Figure 8.(b)), the $50 \mathrm{~Hz}$ resistance is equal to $47 \mathrm{~m} \Omega$ and the $140 \mathrm{kHz}$ series resistance is equal to $227 \mathrm{~m} \Omega$. The copper and core losses can be calculated according to (6) and (7), respectively.

$$
\begin{aligned}
P_{\text {Copper }}= & R_{L F} \cdot I_{L F_{R M S}}^{2}+R_{H F} \cdot I_{H F_{R M S}}^{2} \\
& P_{\text {Core }}=P_{L}-P_{\text {Copper }}
\end{aligned}
$$

Copper losses are equal to $4.98 \mathrm{~W}$, the main part comes from the low frequency current with $4.7 \mathrm{~W}$, the HF losses are equal to $0.28 \mathrm{~W}$. According to the calorimetric measurements the core losses are estimated to be $0.54 \mathrm{~W}$. Therefore, it can be concluded that the conduction losses are the main heat source. Indeed, the injected current is mainly pulsating at $50 \mathrm{~Hz}$. The skin effects are very low and the core is not stressed.

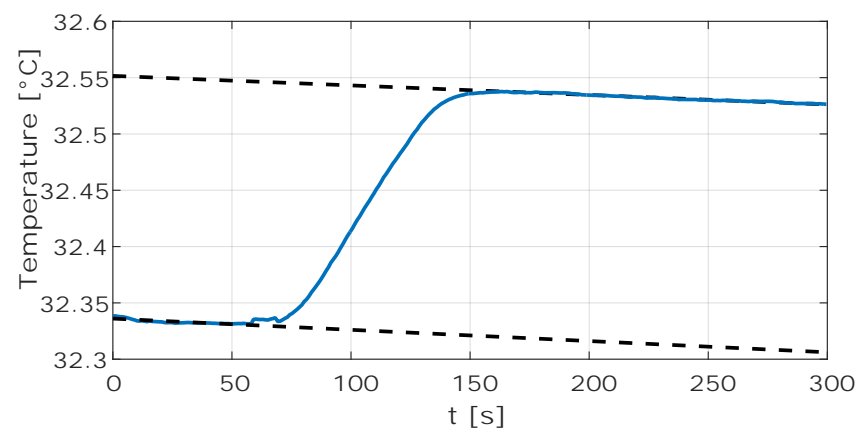

(a) Temperature curve at $10.3 \mathrm{~A}_{\mathrm{RMS}}$

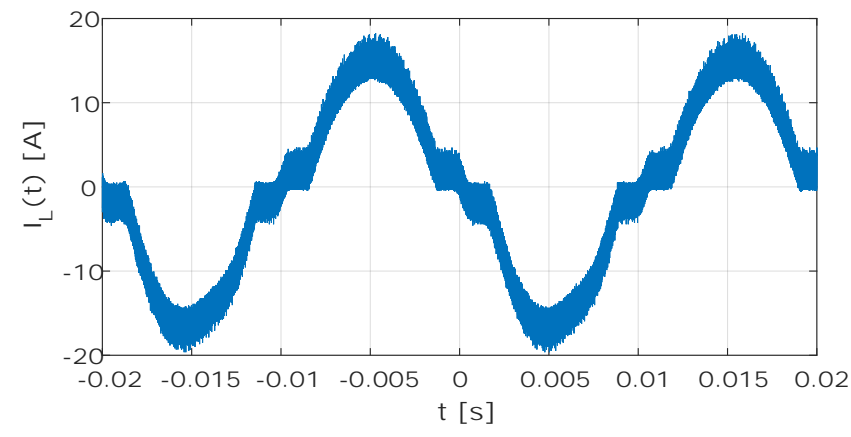

(b) Inductor current $10.3 \mathrm{~A}_{\mathrm{RMS}}$

Figure 12: Results of calorimetric measurements

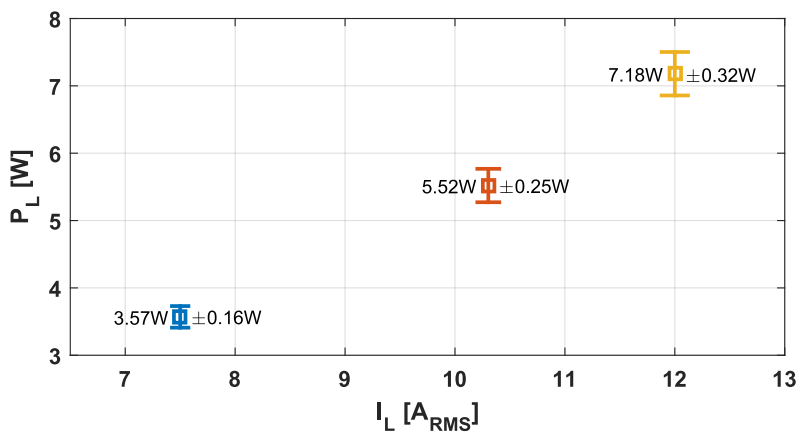

Figure 13: 3D Inductor losses according to the effective current

\section{Thermal measures}

With calorimetric measurements, losses are calculated for fixed current and almost fixed temperature. Since the heating time is very short and the environment does not correspond to the real operational conditions, further tests are performed to analyse the thermal behaviour of the new inductor. The inductor is tested in natural convection cooling under 10.3 $\mathrm{A}_{\mathrm{RMS}}$ (Figure 12.(b)) that corresponds to $5.52 \mathrm{~W}$ dissipated power. The ambient temperature is equal to $25^{\circ} \mathrm{C}$ and the measures are realised with a Fluke Ti10 thermal imaging infrared IR camera, Figure 14. The thermal image shows that the inductor windings are the hottest part. The increase in temperature is about $44{ }^{\circ} \mathrm{C}$, without any cooling system. This indicates with the appropriate cooling system, e.g forced air cooling or custom heat-sink, the proposed inductor is able to support higher current. The 3D PCB design increases the number of surfaces in contact with the air flow that increases the efficiency of the cooling. Thus, the volume of the inductor can be reduced. 


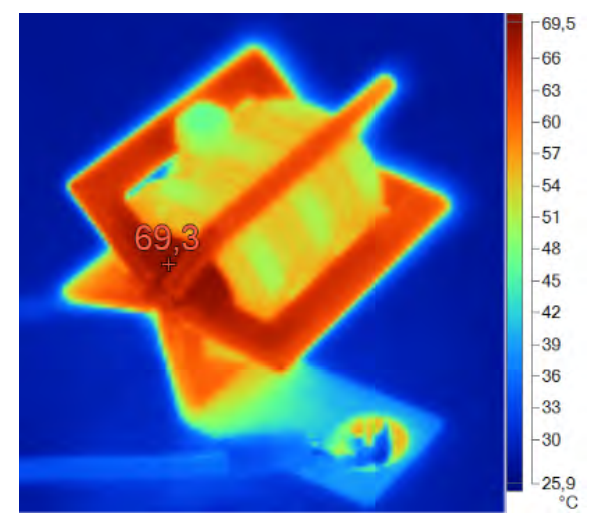

Figure 14: Thermal behaviour investigation at $10.3 \mathrm{~A}_{\mathrm{RMS}}$. IR measurement picture after $10 \mathrm{~min}$ of heating, stable temperature is reached.

\section{CONCLUSION}

PCB embedding is a well known process for small active and passive components. Usually, the power level for applications using PCB embedding is low. The higher the power level, the bigger the components, especially the magnetics, making the embedding process very complicated. It requires large and thin magnetic cores that can be very sensitive during the lamination process. The proposed 3D inductor structure overcomes this issue. The PCB windings are bent around the core without risk of breaking.

The prototype uses the semi-flex ${ }^{\mathrm{TM}}$ PCB technology. The characterisation of the inductor shows good results. Increase in series resistance is acceptable. Nevertheless, the inductor series resistance can still be improved by using PCB with higher number of layers. Moreover, an acceptable volume and footprint is achieved with the proposed concept.

Calorimetric experimental set-up has been settle to further investigate the final design. The experimental conditions were close to the real operation. The thermal behaviour was also analysed in the same conditions. The inductor was tested in natural convection. The performances can be improved with forced air cooling. Tests and simulations validate the concept. Thus, this new design can be used in power converters in the $\mathrm{kW}$ range. The main advantage of the $3 \mathrm{D}$ inductor is the use of semiflex PCBs, permitting further integration freedom. The overall system (including dies, capacitors, resistors, etc) can be designed with more complex shapes without additional connectors for PCB interconnections. The PCB substrate used for the windings can also be used to solder other components, such as current sensors or even series capacitors to build a resonant tank.

\section{REFERENCES}

[1] M. Kasper, D. Bortis, G. Deboy, and J. W. Kolar, "Design of a Highly Efficient $(97.7 \%)$ and Very Compact $\left(2.2 \mathrm{~kW} / \mathrm{dm}^{3}\right)$ Isolated AC-DC Telecom Power Supply Module Based on the Multicell ISOP Converter Approach," IEEE Transactions on Power Electronics, vol. 32, no. 10, pp. 7750-7769, oct 2017.

[2] D. Bortis, D. Neumayr, and J. W. Kolar, " $\eta \rho$-Pareto optimization and comparative evaluation of inverter concepts considered for the GOOGLE Little Box Challenge," in 2016 IEEE 17th Workshop on Control and Modeling for Power Electronics (COMPEL), no. Compel. IEEE, jun 2016, pp. 1-5.
[3] J. S. de Sousa, M. Unger, P. Fulmek, P. Haumer, and J. Nicolics, "Embedded mini heat pipes as thermal solution for PCBs," in 2017 21st European Microelectronics and Packaging Conference (EMPC) \& Exhibition, no. September. IEEE, sep 2017, pp. 1-6.

[4] A. Alderman, L. L. Burgyan, B. Narveson, and E. Parker, "3-D Embedded Packaging Technology: Analyzing its needs and challenges,' IEEE Power Electronics Magazine, vol. 2, no. 4, pp. 30-39, dec 2015.

[5] C. Buttay, C. Martin, F. Morel, R. Caillaud, J. Le Leslé, R. Mrad N. Degrenne, and S. Mollov, "Application of the PCB-Embedding Technology in Power Electronics - State of the Art and Proposed Development," in Internal Symposiumon 3D Power Electronics Integration and Manufacturing (3DPEIM), Berwyn, Maryland, United-States.

[6] Coilcraft, "Shielded Power Inductors XAL1510."

[7] B. Sun, R. Burgos, and D. Boroyevich, "Ultra-low Input-Output Capacitance PCB-Embedded Dual-Output Gate-Drive Power Supply for $650 \mathrm{~V}$ GaN-Based Half-Bridges," IEEE Transactions on Power Electronics, pp. 1-1, 2018.

[8] Murata Power Solutions, "MGJ1 Series 5.7kVDC Isolated 1W SM Gate Drive DC-DC Converters."

[9] M. Ali, E. Labouré, F. Costa, and B. Revol, "Design of a Hybrid Integrated EMC Filter for a DC-DC Power Converter," IEEE Transactions on Power Electronics, vol. 27, no. 11, pp. 4380-4390, nov 2012.

[10] R. Caillaud, C. Buttay, J. Le Leslé, F. Morel, R. Mrad, D. Nicolas, M. Stefan, and C. Combettes, "High power PCB-embedded inductors based on ferrite powder," in 5th Micro/Nano-Electronics Packaging \& Assembly, Design and Manufacturing Forum (MiNaPAD, Grenoble,France, 2017.

[11] R. Caillaud, C. Buttay, R. Mrad, J. Le Leslé, F. Morel, N. Degrenne, and S. Mollov, "Comparison of planar and Toroidal PCB integrated inductors for a multi-cellular $3.3 \mathrm{~kW}$ PFC," in 2017 IEEE International Workshop On Integrated Power Packaging (IWIPP). IEEE, apr 2017, pp. 1-5.

[12] D. Neumayr, D. Bortis, and J. W. Kolar, "Ultra Compact Power Pulsation Buffer for Single-Phase Converter Systems," ECCE Asia, pp. 1-10, 2016.

[13] J. Le Lesle, R. Caillaud, F. Morel, N. Degrenne, C. Buttay, R. Mrad, C. Vollaire, and S. Mollov, "Optimum design of a single-phase Power Pulsating Buffer (PPB) with PCB-integrated inductor technologies," in 2018 IEEE International Conference on Industrial Technology (ICIT), vol. 2018-Febru. IEEE, feb 2018, pp. 782-787.

[14] N. Degrenne, G. Lefevre, and M. Stefan, "A 2W, 5MHz, PCBintegration compatible $2.64 \mathrm{~cm}^{3}$ regulated and isolated power supply for gate driver," in 2016 18th European Conference on Power Electronics and Applications (EPE'16 ECCE Europe). IEEE, sep 2016, pp. 1-10.

[15] T. Ge, Y. Yan, G.-q. Lu, and K. Ngo, “Over-Molded Inductor (OMI)Feasibility Demonstration in a DC-DC Converter," IEEE Transactions on Industrial Electronics, vol. 64, no. 7, pp. 5738-5740, jul 2017. 